\title{
Indice
}

Prefazione VII

G. Azzarello, Il prof. Franco Maltomini: nota biografica e bibliografica 1

\section{TESTI LETTERARI}

A. Monte, Farmaci per una vista migliore: un excursus tra i colliri ỏ 11

Chr. Savino, I manoscritti Marciani del Commento agli Aforismi di Galeno: studi sulla tradizione e sul testo del libro VI

\section{TESTI SEMILETTERARI}

A. Zangrando, Per aspera ad astra: le strane divisioni di P.Rain. Unterricht kopt. 326

\section{TESTI DOCUMENTARI}

\section{ETÀ TOLEMAICA}

S. De Bortoli, Uno scriba un po' disattento, ma solerte: osservazioni alla dinamica di compilazione e revisione di P.Eleph. 1 75

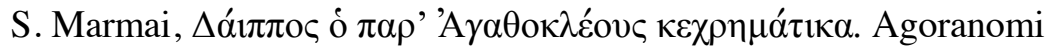
nell'Egitto tolemaico: una sintesi storico-papirologica

\section{ETÀ BIZANTINA}

E. Balossi, Un nuovo dossier bizantino dall'Eracleopolite: i papiri del phrontistes Phoibammon e di suo padre Peetas

E. Bonollo \& R. Coden, Pratiche notarili nell'Ossirinchite di età bizantina: i papiri di Papnuthios e Ioannes

A. Calabretto, Tre ipotesi di lettura a P.Oxy. XVI 1925

V. Covre, Vecchie ricevute e nuove interpretazioni: SB XXII 15487 e la beneficenza apionica

A. Ghezzo, Notai, scribi e stallieri nell'Ossirinchite di età bizantina: il caso di Iustos, Ioannes e Georgios 
L. Putelli, Le lettere di Biktor, antigeuchos degli Apioni, a Georgios

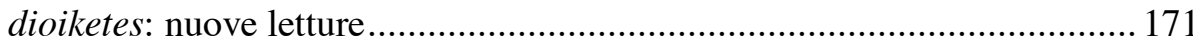

F. Silveri, Menas oiké́tnৎ degli Apioni tra realtà e finzione: la formula di rappresentanza nei papiri e la legge di Giustiniano ................ 181

A. Tomat, Il dossier dello scholastikos Flavios Hermias ................................ 191

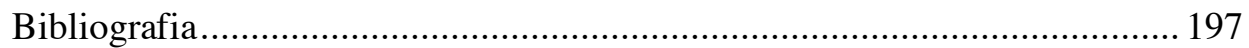

Notizia biografica sulla curatrice, le autrici e l'autore degli scritti

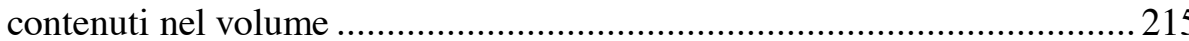

Indici 